\title{
Retraction Note: A new compaction strategy for enhancing the utilization of reconfigurable chips
}

\author{
A. I. Saleh ${ }^{1}$
}

Published online: 13 June 2015

(C) Springer-Verlag London 2015

Retraction to: Int J Adv Manuf Technol

DOI: 10.1007/s00170-012-4497-1

Springer has decided to retract the following article "A new compaction strategy for enhancing the utilization of reconfigurable chips" in International Journal of Advanced Manufacturing Technology, 67(1-4). Upon investigation carried out according to the Committee on Publication Ethics guidelines, it has been found that the authors have duplicated substantial parts from the following article:

"A Novel Puzzle Based Compaction (PBC) Strategy for Enhancing the Utilization of Reconfigurable Resources", 'International Journal of Applied Evolutionary Computation' 1(4), pp. 34-70.

The online version of the original article can be found at http://dx.doi.org/ 10.1007/s00170-012-4497-1.

A. I. Saleh

aisaleh@yahoo.com

1 Department of Computer Eng. \& Systems, Faculty of Engineering, Mansoura University, Mansoura, Egypt 